\title{
PENERAPAN METODE LANDSCAPE-URBANISM DALAM PERANCANGAN RUANG REKREASI KEBUGARAN DI SAWANGAN DEPOK
}

\author{
Glenn Geraldi ${ }^{1)}$, Tony Winata ${ }^{2)}$ \\ 1)Program Studi S1 Arsitektur, Fakultas Teknik, Universitas Tarumanagara, glenngeraldi@gmail.com \\ 2)Program Studi S1 Arsitektur, Fakultas Teknik, Universitas Tarumanagara, tonywinata@ft.untar.ac.id
}

\begin{abstract}
Abstrak
Inside Out: Ruang Rekreasi Kebugaran Sawangan merupakan proyek yang bertujuan untuk meningkatkan kualitas gizi dan kesadaran pentingnya perilaku hidup sehat di tengah kepadatan ekologi perkotaan. Kondisi demografi masyarakat memasuki usia produktif (15-64 tahun) di tahun 2020-2030 mendorong dibutuhkannya proyek ini sebagai bagian dari 'investasi bonus demografi. Populasi lingkungan perkotaan semakin padat akibat peningkatan urbanisasi. Percepatan waktu dan ruang membuat lingkungan perkotaan tidak kondusif untuk aktivitas fisik yang menyehatkan dan masyarakat juga lebih mudah terpapar lingkungan obesogenik. Buruknya asupan gizi dan kurangnya perilaku hidup sehat menjadi permasalahan yang perlu diatasi. Konsep yang diusung adalah keseimbangan antara kebutuhan jasmani dan kebutuhan batin yang diperoleh dari lingkungan alam sendiri. Proyek ini dirancang dengan metode landscape-urbanism dengan parameter beyond ecology untuk mengintegrasikan prinsip lansekap ke dalam lingkungan perkotaan yang diharapkan membawa kebaikan bagi kesehatan masyarakat.
\end{abstract}

Kata kunci: kebugaran; kesehatan; perkotaan; rekreasi

\begin{abstract}
Inside Out: Sawangan Fitness Recreation Space is a project that aims to improve the quality of nutrition and the importance of healthy living behavior awareness in the midst of urban ecological density. Demographic condition of people entering their productive age (15-64 years) in 2020-2030 encourages the need for this project as part of the 'demographic bonus investment'. The population of urban environment is getting denser due to increasing urbanization. Acceleration of time and space makes urban environment less conducive to healthy physical activities and people are more easily exposed to obesogenic environments. Poor nutritional intake and lack of healthy living habits are problems that need to be solved. The concept is a balance between physical needs and mental needs that are obtained from the natural environment itself. This project is designed with landscape-urbanism method with beyond ecology parameter to implement landscape principals into urban environment which is expected to bring good health for urban communities.
\end{abstract}

Keywords: fitness; healthyness; recreation; urban

\section{PENDAHULUAN}

\section{Latar Belakang}

Kondisi demografi Indonesia memasuki fase 'bonus demografi' pada tahun 2020-2030 ketika proporsi orang dalam kelompok usia produktif (15-64 tahun) mencapai maksimum dan rasio ketergantungan berada pada tingkat terendah (Bappenas, 2019). Produktivitas ekonomi dengan demikian perlu dioptimalkan. Anak-anak dan remaja saat ini akan membentuk angkatan kerja yang produktif di tahun 2020-2030. Sisi negatif dari fenomena demografi ini adalah setidaknya sepertiga anak dan remaja saat ini mengalami stunting (pertumbuhan terhambat) dan akan kurang produktif di masa depan. Sisi positifnya adalah terdapat peluang untuk mengurangi 
Beban Ganda Masalah Gizi, mengembangkan pola makan yang sehat, serta berinvestasi dalam 'bonus demografi' (Bappenas, 2019).

Selain kondisi demografi yang potensial, terjadi peningkatan migrasi dari pedesaan ke daerah perkotaan. Populasi perkotaan meningkat dari $42 \%$ pada tahun 2000 menjadi $50 \%$ pada tahun 2010 dan diperkirakan akan meningkat menjadi 67\% pada 2035 (Bappenas, 2019). Lingkungan perkotaan yang semakin padat mengalami percepatan waktu dan ruang dengan bantuan teknologi virtual membuat aktivitas lebih banyak dilakukan dari rumah (from home). Lingkungan perkotaan menjadi tidak kondusif untuk aktivitas fisik yang menyebabkan minimnya olahraga yang berdampak terhadap penambahan berat badan dan obesitas. Buruknya asupan gizi dan kurangnya perilaku hidup sehat menjadi permasalahan yang perlu diatasi. Urbanisasi justru menjadi peluang untuk menjangkau lebih banyak orang dengan lebih mudah melalui pesan dan aksi untuk mempromosikan makanan dan gaya hidup yang lebih sehat. Oleh karena itu diharapkan arsitektur mampu berkontribusi dalam pengembangan pola hidup sehat ditengah keriuhan kota Jakarta.

\section{Rumusan Permasalahan}

Rumusan masalah dari latar belakang diatas yaitu bagaimana rancangan arsitektur dapat berkontribusi dalam meningkatkan kualitas gizi dan perilaku hidup sehat masyarakat di tengah kepadatan ekologi perkotaan?

\section{Tujuan}

Proyek ini menjadi wadah yang bertujuan untuk meningkatkan kualitas gizi dan perilaku hidup sehat masyarakat di tengah kepadatan ekologi perkotaan yang dicapai dengan cara seperti menyediakan kebutuhan konsumsi gizi yang sehat; mendistribusikan produk seputar healthy lifestyle; meningkatkan kesadaran pentingnya hidup sehat; mewadahi aktivitas olahraga dan rekreasi masyarakat.

\section{KAJIAN LITERATUR}

\section{Beyond Ecology}

Bagaimana arsitektur melampaui Ekologi? Jawabannya adalah kemampuan untuk melihat lingkungan binaan yang penuh dengan objek ekosistem dan bangunan yang dirancang harus sebagai 'rumah' - 'oikos' bagi manusia di bumi. Rentang keterbacaan arsitektur sebagai 'oikos' menggemakan spektrum keruangan yang mudah dipahami dalam citra dan gunanya. Kita percaya bahwa arsitektur berbicara melalui ruang dan waktu, dalam bahasa fungsional, struktural, material, formal, teknis, tipologis, dan melalui tampilan semiotik ikon, indeks serta simbol-simbol. Pada titik yang lainnya, adalah tentang bagaimana arsitektur mempengaruhi ranah publik dalam masalah sosial, budaya, politik, ekonomi dan lingkungannya. (Sutanto, 2020) Bagaimana arsitektur 'Melampaui' Ekologi? Jawabannya adalah akan ada cara konsumsi baru tentang konsep keruangan, lebih lokal dalam hal konten dan lebih memperhatikan produksi budaya daripada hanya konsumsi budaya. Sekarang ini, dunia produksi dan pekerjaan akan mengalami revolusi karena telework, kerja jarak jauh, untuk pekerjaan non-manual, akan berlaku di mana-mana. Bahkan yang manual pun akan sangat dipengaruhi oleh otomatisasi, robotisasi, proses teknologi bantuan jarak jauh. Pada dasarnya, kemajuan teknologi akan dipercepat. Ruang menjadi begitu 'fleksibel' dan 'mengambang' dan akan terus mencari jawaban terhadap perubahan ekosistem yang sedang berlangsung dan pertanyaannya adalah mampukah kita melampauinya?. Melampaui ekologi adalah sebuah kondisi ekosistem yang formasi sosial dan spasialnya mengalami kecepatan dan percepatan. Pandemi tidak bisa diprediksi kapan akhirnya, tapi akibat yang ditimbulkannya akan terus berlangsung, yakni pemadatan waktu dan pendefinisian kembali konsep ruang spasial. Suatu karya arsitektur bisa 
dikatakan melampaui ekologi bila memenuhi parameter: energi dan emisi, adaptasi, ketahanan, keberlanjutan, teknologi baru, dan kontekstual (Sutanto, 2020).

\section{Parameter Beyond Ecology}

6 Parameter suatu rancangan arsitektur dapat dikatakan beyond ecology menurut Agus Susanto antara lain berupa pemenuhan dalam aspek emisi, energi, adaptif, teknologi baru, kontekstual, ketahanan, dan keberlanjutan.

\section{Landscape-Urbanism}

Sejak tahun 1995, Landscape-Urbanism telah menjadi wacana baru sebagai sebuah pendekatan desain untuk pembentukan kota kontemporer. Bagi pendukung Landscape-Urbanism, bahwa pendekatan konvensional dan tradisional tentang desain perkotaan dianggap tidak valid untuk menggambarkan kondisi dan ranah ruang kota kontemporer. Kondisi perkembangan morfologi kota yang sudah berkembang dalam kompleksitas dinamis melalui layer-layer seperti aspek ekologis, infrastruktur, formasi sosial, kondisi digital dan resilience (ketahanan), dll sehingga membutuhkan metode dan model baru ketika mendekati kota (Sutanto, 2020).

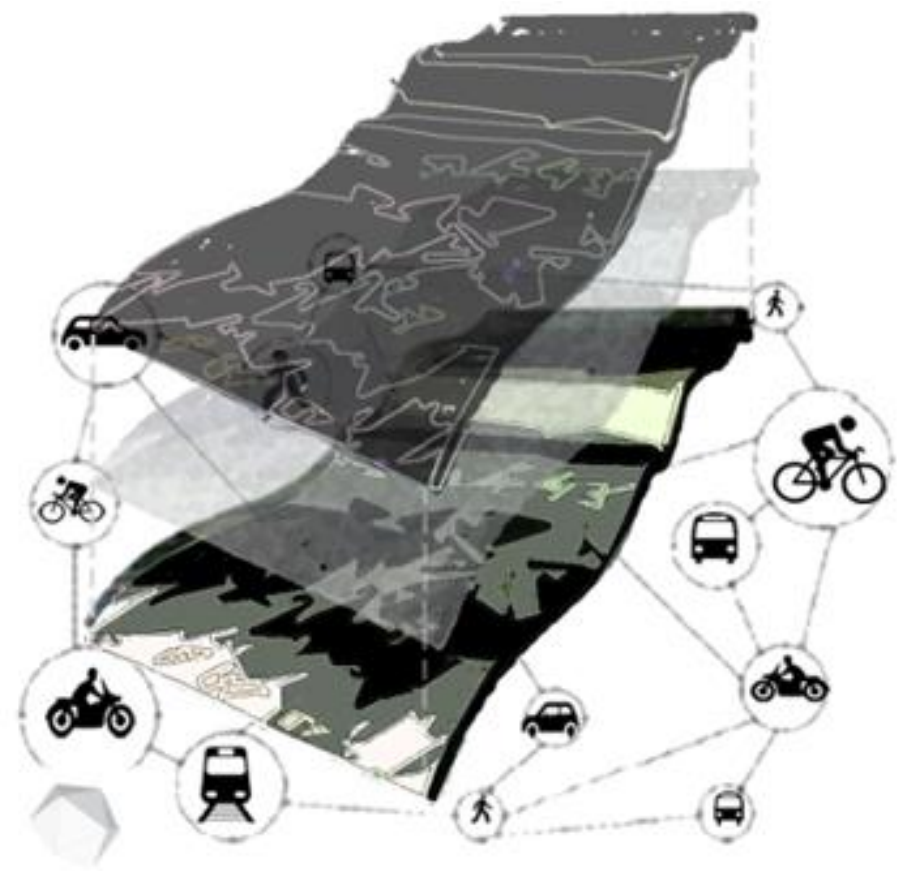

Gambar 1. Diagram Landscape-Urbanism Sumber: Penulis, 2021

Hanna Assargard mengatakan Landscape-Urbanism memberikan kesempatan untuk menarik inspirasi dari fungsi dan aspek operasional lansekap dalam layer-layer pembentuknya, daripada hanya kualitas estetika. Revaluasi bentang alam sebagai lansekap menyiratkan fokus pada proses, kontingensi dan integrasi proses keruangan kota (seperti : sosial, budaya, ekonomi, politik, lingkungan) dari waktu ke waktu. Pemikiran ini agaknya merupakan tattakan dasar berpikir dalam landscape urbanism dan memberi peluang sebagai konsep dan konstruksi terbuka untuk beberapa interpretasi. Charles Waldheim berpendapat bahwa untuk memahami metropolis abad kedua puluh satu diperlukan ide dan metode baru, seperti yang dikatakannya "pemahaman tradisional kota sebagai ekstrapolasi model arsitektur dan metafora tidak lagi memungkinkan mengingat prevalensi kekuatan atau aliran yang lebih besar. Ini termasuk pecah atau pecahnya logika arsitektonis bentuk urban tradisional yang didorong oleh perubahan ekologis, infrastruktur, atau ekonomi. "Konstruksi spasial kota global dan lingkungan kotanya, 
seharusnya tidak lagi melekat pada fungsi-fungsi yang berdiri sendiri, tetapi sebaliknya harus berintegrasi ke dalam jalinan kota secara keseluruhan. Kota akan selalu tumbuh dalam dinamika dan problemnya masing-masing karena ketelitian membacar layer-layer dari sistem struktur kota akan membangun masa depan kota yang tidak statis.

Landscape-Urbanism adalah adalah teori desain perkotaan yang menyatakan bahwa kota ini dibangun dari kondisi lapangan horizontal yang saling berhubungan dan kaya secara ekologis, bukan penataan benda dan bangunan. Urbanisme Lansekap, seperti Urbanisme Infrastruktur dan Urbanisme Ekologis, menekankan kinerja daripada estetika murni dan menggunakan pemikiran berbasis sistem dan strategi desain. Ungkapan 'urbanisme lanskap' pertama kali muncul pada pertengahan 1990-an. Sejak saat ini, frasa 'urbanisme lanskap' telah mengambil banyak kegunaan yang berbeda, tetapi paling sering disebut sebagai respons postmodernis atau postmodernis terhadap "kegagalan" Urbanisme Baru dan pergeseran dari visi dan tuntutan yang komprehensif, untuk arsitektur modern dan perencanaan kota (Sutanto, 2020).

\section{Elemen Pembentuk Citra Kota Menurut Kevin Lynch}

Dalam bukunya Image of The City, Kevin Lynch mengungkapkan ada 5 elemen pembentuk wajah kota secara fisik yaitu: path (jalur), edge (tepian), district (kawasan), nodes (simpul), dan landmark (penanda). Kelima elemen ini dirasa dapat mewakili cita rasa dari suatu kawasan dan memberikan citra yang kuat terhadap kota. Kelima elemen ini digunakan untuk membentuk mental map (peta mental) yang digunakan untuk memudahkan mengingat atau merekam elemen-elemen fisik dalam suatu kota (Lynch,1960).

\section{Elemen Path (Jalan/Jejalur)}

Path adalah jalur-jalur dimana pengamat biasanya bergerak dan melaluinya. Path dapat berupa jalan raya, trotoar, jalur transit, canal, jalur kereta api. Bagi banyak orang, ini adalah elemen dominan dalam gambaran mereka. Orang mengamati kota sambil bergerak melaluinya, dan sepanjang path elemen-elemen lingkungan lain diatur dan berhubungan. Path (jalan) secara mudah dapat dikenali karena merupakan koridor linier yang dapat dirasakan oleh manusia pada saat berjalan mengamati kota. Struktur ini bisa berupa gang-gang utama, jalan transit, jalan mobil/ kendaraan, pedestrian, sungai, atau rel kereta api. Untuk kebanyakan orang, jalan adalah elemen kota yang paling mudah dikenali, karena semua manusia menikmati kota pada saat dia berjalan. Jadi didalam elemen ini mengandung pengertian jalur transportasi linier yang dapat dirasakan manusia.

\section{Elemen Edges (Tepian)}

Edges adalah elemen linear yang tidak digunakan atau dipertimbangkan sebagai path oleh pengamat. Edges adalah batas-batas antara dua wilayah, sela-sela linier dalam kontinuitas: pantai, potongan jalur kereta api, tepian bangunan, dinding. Edges juga merupakan elemen linier yang dikenali manusia pada saat dia berjalan, tapi bukan merupakan jalur/paths. Batas bisa berupa pantai, dinding, deretan bangunan, atau jajaran pohon/ lansekap. Batas juga bisa berupa barrier antara dua kawasan yang berbeda, seperti pagar, tembok, atau sungai. Fungsi dari elemen ini adalah untuk memberikan batasan terhadap suatu area kota dalam menjaga privasi dan identitas kawasan, meskipun pemahaman elemen ini tidak semudah memahami paths.

\section{Elemen District (Distrik)}

Distrik (district) adalah kawasan kota yang bersifat dua dimensi dengan skala kota menengah sampai luas, dimana manusia merasakan 'masuk' dan 'keluar' dari kawasan yang berkarakter beda secara umum. Karakter ini dapat dirasakan dari dalam kawasan tersebut dan dapat dirasakan juga dari luar kawasan jika dibandingkan dengan kawasan dimana si pengamat 
berada. Elemen ini adalah elemen kota yang paling mudah dikenali setelah jalur/paths, meskipun dalam pemahaman tiap individu bisa berbeda. Districts merupakan wilayah yang memiliki kesamaan (homogen). Kesamaan tadi bisa berupa kesamaan karakter/ciri bangunan secara fisik, fungsi wilayah, latar belakang sejarah dan sebagainya.

\section{Elemen Nodes (Simpul)}

Nodes adalah titik-titik, spot-spot strategis dalam sebuah kota dimana pengamat bisa masuk, dan yang merupakan fokus untuk ke dan dari mana dia berjalan. Nodes bisa merupakan persimpangan jalan, tempat break (berhenti sejenak) dari jalur, persilangan atau pertemuan path, ruang terbuka atau titik perbedaan dari suatu bangunan ke bangunan lain. Elemen ini juga berhubungan erat dengan elemen district, karena simpul-simpul kota yang kuat akan menandai karakter suatu district. Untuk beberapa kasus, nodes bisa juga ditandai dengan adanya elemen fisik yang kuat. Nodes menjadi suatu tempat yang cukup strategis, karena bersifat sebagai tempat bertemunya beberapa kegiatan/aktifitas yang membentuk suatu ruang dalam kota.

\section{Elemen Landmark (Penanda)}

Landmark adalah titik-acuan dimana si pengamat tidak memasukinya, mereka adalah di luar. Landmark biasanya merupakan benda fisik yang didefinisikan dengan sederhana seperti: bangunan, tanda, toko, atau pegunungan. Beberapa landmark adalah landmark-landmark jauh, dapat terlihat dari banyak sudut dan jarak, atas puncak-puncak dari elemen yang lebih kecil, dan digunakan sebagai acuan orintasi. Landmark-landmark lain adalah yang bersifat lokal, hanya bisa dilihat di tempat-tempat yang terbatas dan dari jarak tertentu. ini adalah tanda-tanda yang tak terhitung, depan-depan toko, pohon-pohon, gagang pintu, dan detail perkotaan lain, yang mengisi citra dari sebagian besar pengamat. Mereka sering digunakan sebagai petunjuk identitas dan bahkan struktur, dan diandalkan karena perjalanan menjadi semakin familiar.

\section{METODE}

Tahapan perancangan diawali dari penentuan program yang akan diakomodasi sesuai dengan tujuan proyek. Kemudian, dilakukan pemilihan lokasi berdasarkan kriteria kontekstual topik seputar pola hidup sehat dalam ekologi kota yang mengalami percepatan waktu dan ruang. Parameternya meliputi kepadatan penduduk, tingkat kesehatan, dan parameter Perilaku Hidup Bersih dan Sehat. Dari pilihan tapak yang sesuai dengan kriteria, dipilih satu tapak dengan metode analisis strenght, weakness, opportunity, dan thread. Tapak dianalisis secara makro, messo, dan mikro untuk menghasilkan zoning pada tapak. Kemudian masuk ke tahapan transformasi massa menggunakan metode Landscape-Urbanism dan disempurnakan dengan prinsip teori wajah kota dari Kevin Lynch. Massa yang terbentuk akan diolah lebih detail dalam hal tata ruang, struktur, dan tampak bangunan.

\section{DISKUSI DAN HASIL}

\section{Program}

Proyek ini diharapkan mampu berkontribusi dalam pengembangan gizi dan perilaku hidup sehat. Konsep yang digunakan adalah keseimbangan antara kebutuhan jasmani dan kebutuhan batin yang diperoleh dari lingkungan alam sendiri. Pemenuhan kebutuhan manusia ini tetap mempertahankan keseimbangan dengan kebutuhan alam. Kebutuhan kesehatan fisik yang dipenuhi baik melalui program distribusi konsumsi sehat, maupun melalui program aktivitas fisik (olahraga). Kebutuhan mental yang sehat juga terpenuhi oleh program rekreasi dan interaksi yang playfull yang melibatkan pemeliharaan alam di dalamnya. 


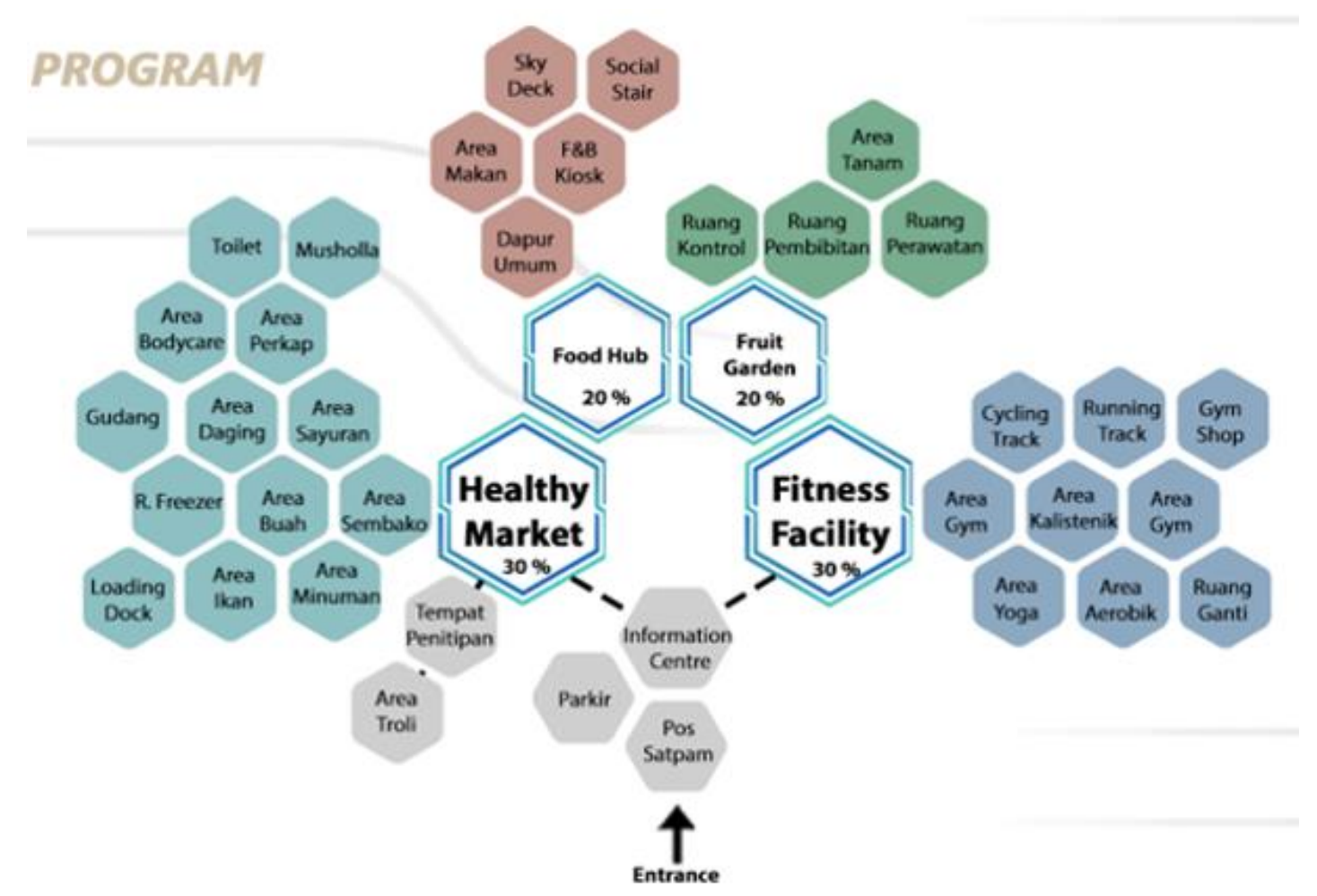

Gambar 2. Diagram Program

Sumber: Penulis, 2021

\section{Healthy Market}

Pasar sehat yang berorientasi ke arah convinience store merupakan tempat distribusi konsumsi sehat dan kaya gizi berupa produk hortikultur (sayur dan buah), sembako, ikan, daging, minuman, dan perlengkapan lain yang berkaitan dengan kesehatan. Sistem pasar sehat ini memadukan prinsip offline shopping yang menawarkan pengalaman berbelanja dengan kemampuan melihat langsung barang yang dibeli dengan sistem online shopping yang menggunakan bantuan teknologi dan aplikasi dalam tahap memperoleh informasi produk hingga dalam hal transaksi tanpa antre. Hal ini bertujuan untuk memberikan pengalaman berbelanja yang mudah dan menyenangkan.

\section{Fitness Facility}

Program ini mewadahi aktivitas berolahraga untuk memenuhi kebutuhan fisik dan mental. Jenis olah raga bersifat umum untuk semua kalangan seperti gym area, jogging, aerobic, yoga, bersepeda, zona anak-anak, dan calisthenic gym. Sebagian program ini dibuat di ruang terbuka dengan beberapa tempat yang memiliki atap. Fasilitas mengintegrasikan teknologi yang mampu mengubah energi dari aktivitas fisik menjadi energi listrik yang dapat digunakan untuk proyek ini. Pengunjung yang 'menghasilkan energi' diberi imbalan baik berupa voucher belanja, konsumsi sehat.

\section{Analisis Tapak}

Tapak yang terpilih adalah tapak di Kelurahan Kedaung yang berada di Jalan Raya ParungCiputat, Kelurahan Kedaung, Kecamatan Sawangan, Depok yang memiliki parameter tingkat Perilaku Bersih dan Sehat terendah sebesar 63,64\% (Dinas Kesehatan Kota Depok, 2019). Tapak memiliki luas sekitar 17 ribu meter persegi. Tapak memiliki luas sekitar 17 ribu meter persegi. Land use di sekitar tapak terutama yang berbatasan dengan Jalan Raya Parung-Ciputat berupa zona komersil/industri dan permukiman. zona persawahan dan perkebunan masih cukup banyak di sebelah Timur dan Barat Daya tapak. 
Bangunan di sekitar tapak terdiri dari bangunan tradisional maupun modern yang memiliki ketinggian 1-3 lantai. Massa dan persebaran bangunan di sebelah Barat tapak memiliki proporsi yang lebih masif dan tertata relatif terhadap sebelah Utara, Timur, dan Selatan tapak yang memiliki permukiman dengan persebaran yang lebih acak. Kondisi eksisting tapak berupa lahan kosong dengan akses jalan kolektor primer selebar 10 meter yang terdiri dari 2 arah jalur masingmasing 2 lajur. Lebar jalan lokal primer sekitar 5 meter yang terdiri dari 1 lajur tapi dapat digunakan 2 arah.

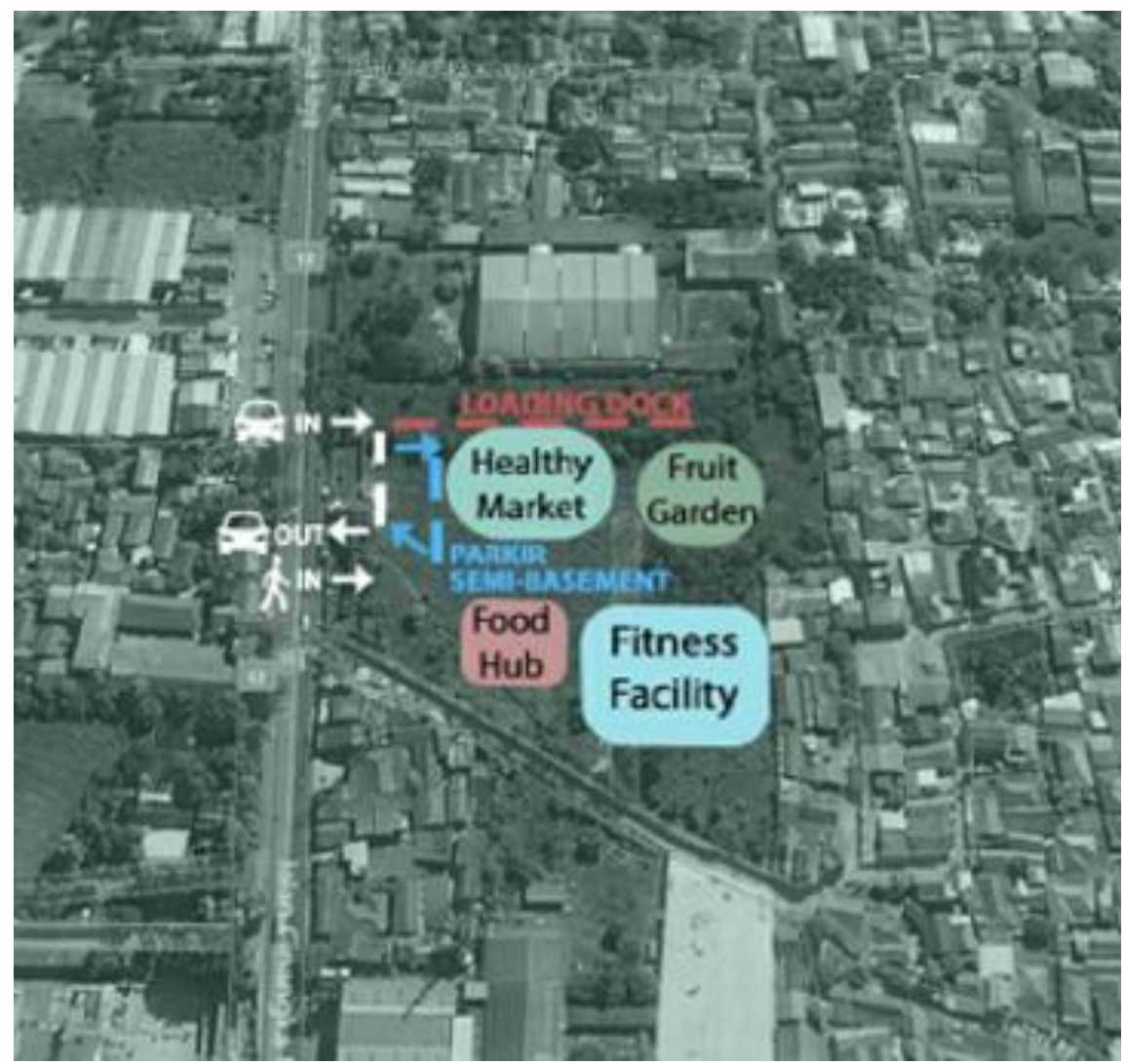

Gambar 3. Diagram Zoning

Sumber: Penulis, 2021

Healthy market dan food hub berada di dekat entrance utama mengingat fungsi komersilnya yang membutuhkan zona publik sedangkan fitness facility dan fruit garden berada di bagian belakang tapak agar jauh dari keramaian jalan raya karena memerlukan zona yang lebih privat. Akses masuk dibuat dari jalan raya (sebelah Barat tapak) beserta akses loading dock di sepanjang pinggri tapak bagian Utara.

\section{Proses Transformasi Massa}

Zoning 2D dari hasil analisis tapak dilanjutkan dalam proses transformasi massa yang berdasarkan metode Landscape-Urbanism dan perwujudan unsur elemen kota Kevin Lynch. 
1 Peletakkan massa program makro sesuai zoning hasil analisis tapak

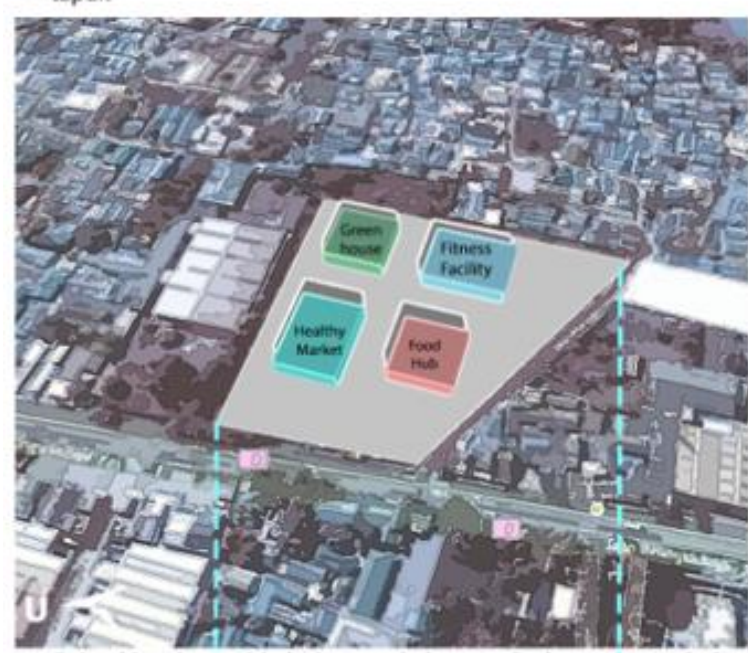
2 Peletakkan layer sirkulasi manusia berupa Path yang menghubungkan yang mampu diakses sepeda, skateboard, hingga kursi roda

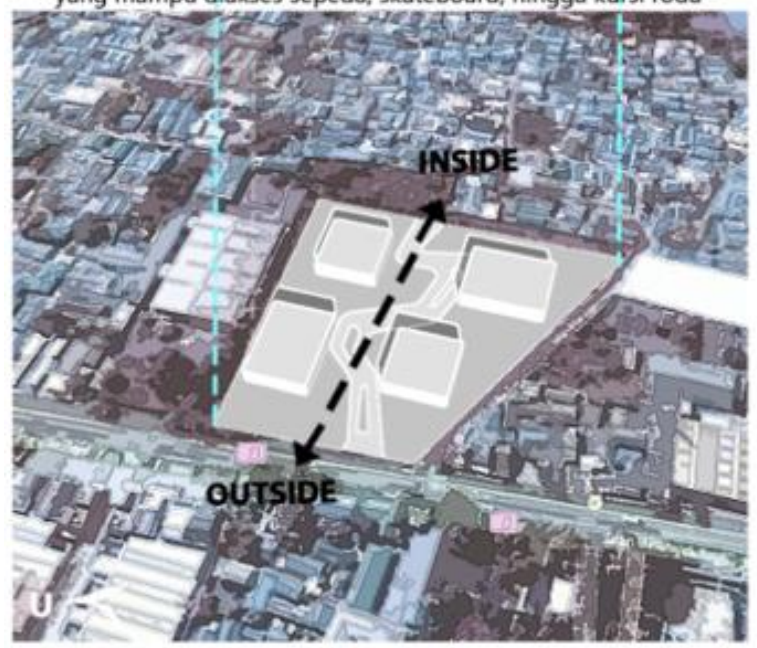

3 Penyesuaian tepian massa (edge) mengikuti jalur sirkulasi (poth)dengan aksen lengkung di bagian dalam (inside) dar aksen runcing di bagian luar (outside)

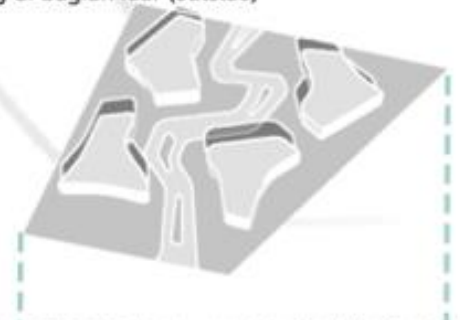

4 Layer kendaraán berupa akses yang terpisah dari pedestrian akses looding dock. Peletakan nodes dengan landmark di tengah jalur sirkulasi.

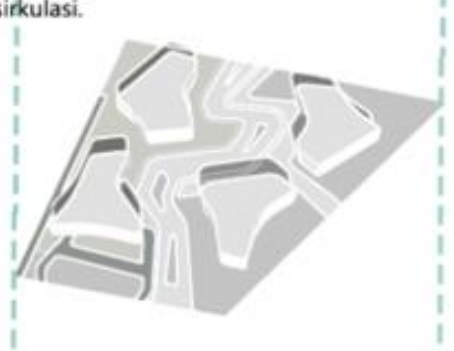

5 Penataan layet sirkulasi antar program dan layer landscape. Pengolahan sclid-void massa membentuk suatu kesaniaan wujud bangunan (district)

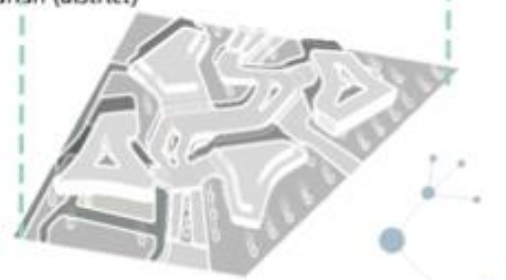

Gambar 4. Diagram Transformasi Massa Sumber: Penulis, 2021

Perwujudan bangunan melalui tahapan transformasi massa yaitu peletakkan massa program makro sesuai zoning hasil analisis tapak dengan titik berat pada analisis akses dan view; peletakkan layer sirkulasi manusia berupa path yang menghubungkan akses utama dari jalan raya ke permukiman berupa jalur pedestrian yang mampu diakses sepeda, skateboard, hingga kursi roda; penyesuaian tepian massa (edge) mengikuti jalur sirkulasi (path) dengan aksen lengkung di bagian dalam (inside) dan aksen runcing di bagian luar (outside); layer kendaraan berupa akses yang terpisah dari pedestrian, akses loading dock. Peletakan nodes dengan landmark di tengah jalur sirkulasi; penataan layer sirkulasi antar program dan layer landscape. Pengolahan solid-void massa membentuk suatu kesamaan wujud bangunan (district). 


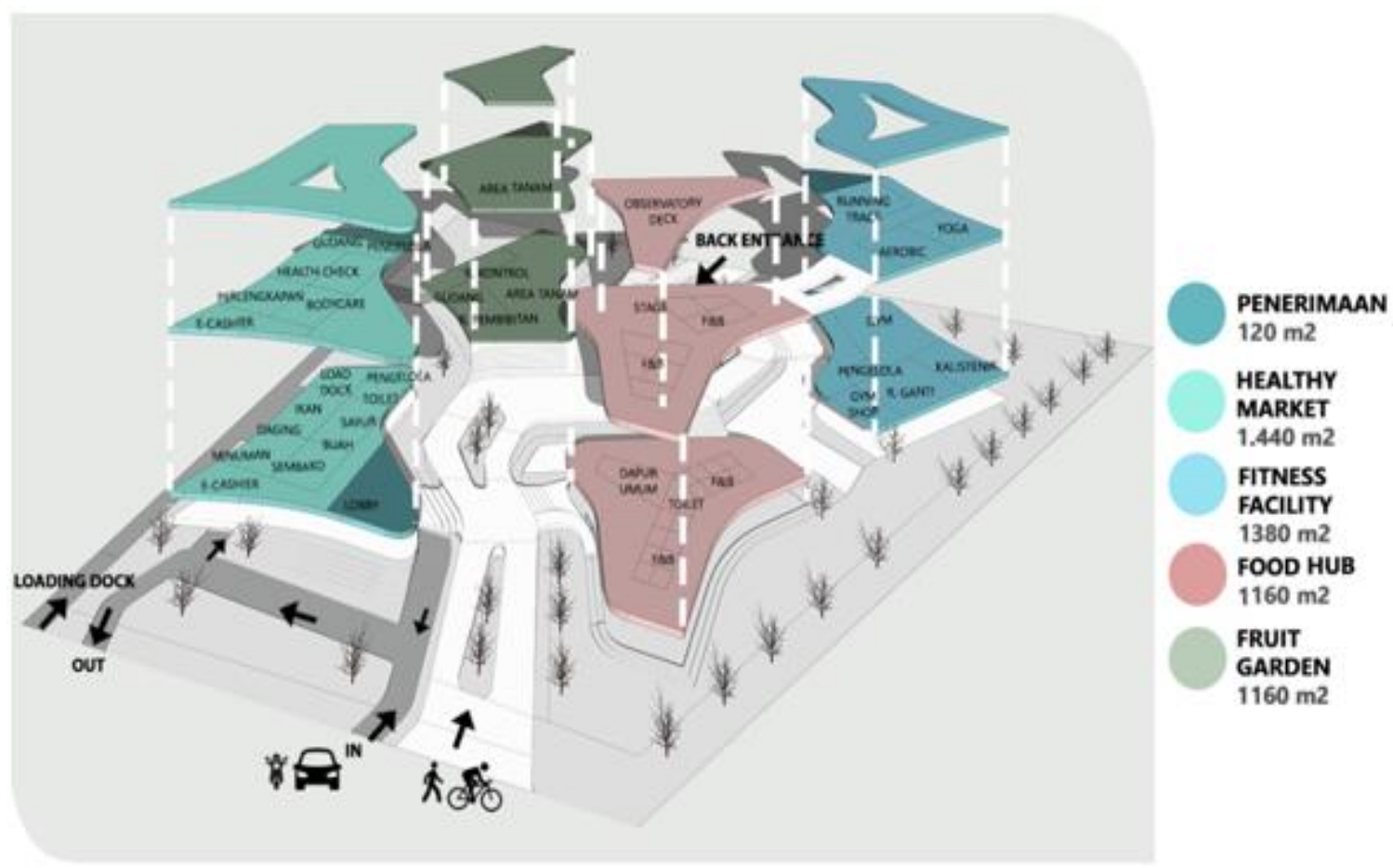

Gambar 5. Diagram Zoning 3D

Sumber: Penulis, 2021

Setelah gubahan massa tercipta melalui metode landscape urbanism dan penerapan unsur pembentuk citra kota menurut Kevin Lynch, dibuatlah zoning 3D untuk menata layout dalam setiap massa sesuai dengan program ruang.

\section{Penerapan Parameter Beyond Ecology}

Gubahan massa yang dihasilkan beserta zoning skematis keruangan menjadi dasar dalam pengembangan ide bentuk bangunan yang menerapkan parameter beyond ecology di dalamnya. Penerapan dalam bangunan antara lain mengurangi penggunaan energi dan emisi dengan mewujudkan konsep bangunan ramah lingkungan yang 'terbuka' dengan menerapkan prinsip bangunan tropis berupa penggunaan teritis. Penerapan prinsip Open-Plan yang memungkinkan penggunaan fungsi yang Adaptif. Teknologi baru dengan mengintegrasikan Al dalam sistem penggunaan energi maupun sistem yang mempermudah pengunanya. Kontekstual lingkungan sekitarnya menjadi dasar integrasi terhadap prinsip lansekap. Ketahanan dan keberlanjutan diwujudkan dalam parameter sustainable. 


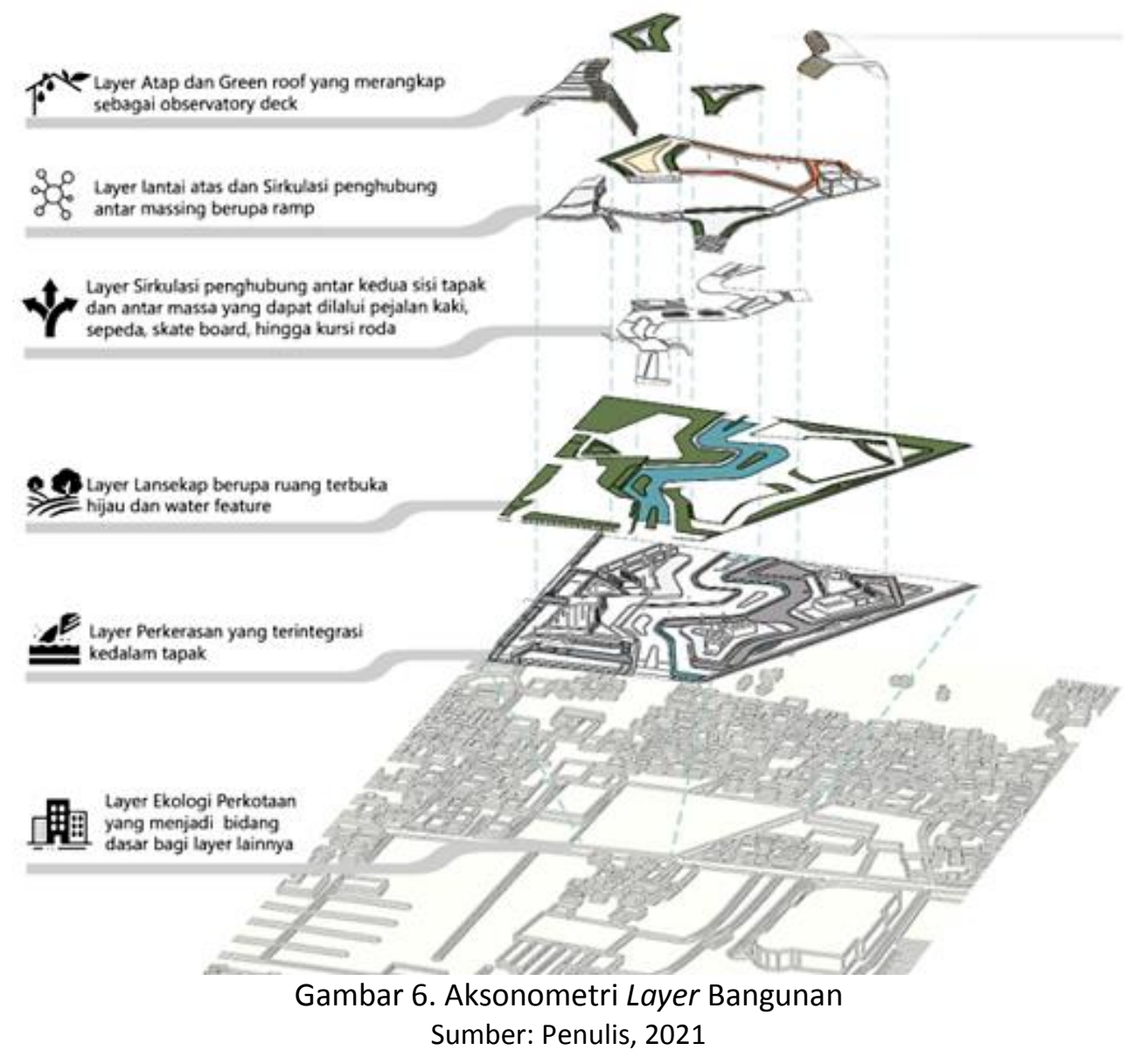

Diagram diatas menunjukkan susunan layer yang terbentuk pada bangunan mulai dari layer ekologi perkotaan yang menjadi dasar bagi layer diatasnya. Layer perkerasan dan lansekap yang terintegrasi ke dalam tapak dengan mengkombinasikan unsur perkerasan buatan, lansekap dan water feature. Layer sirkulasi yang menjadi titik berat design yang menghubungkan kedua sisi tapak dan hubungan antar massa dalam tapak di level lantai 1 dan 2. Layer penutup atap berupa green roof yang terintegrasi dengan green wall serta dapat berfungsi sebagai observatory deck.

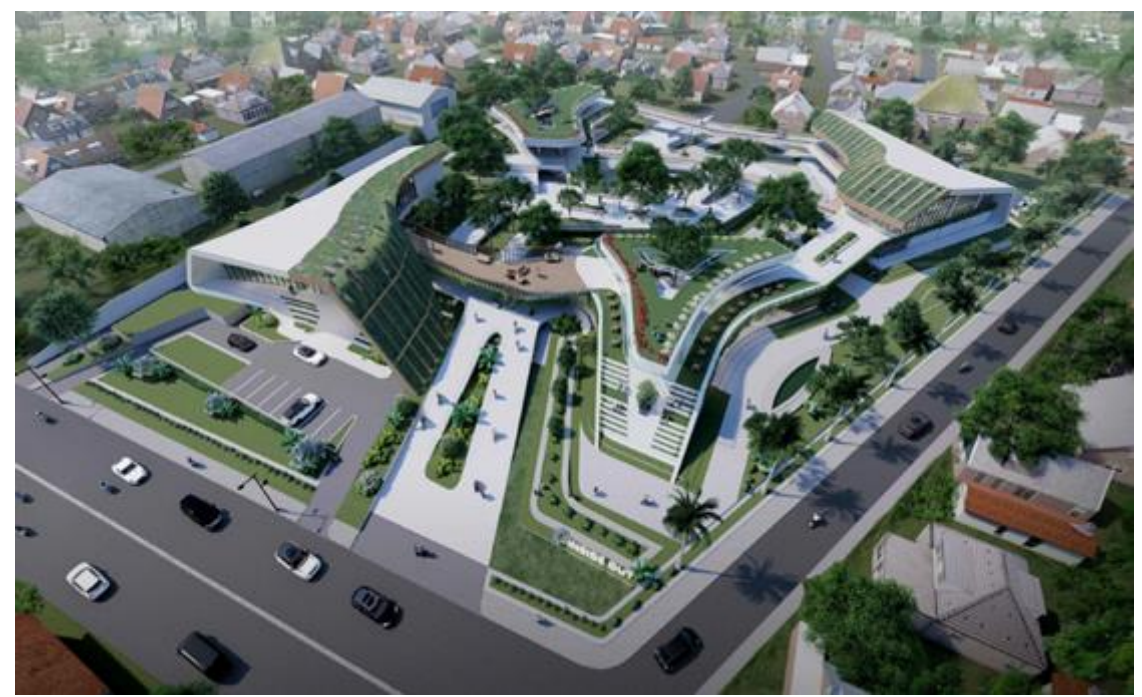

Gambar 7. Ilustrasi Bird Eye View Sumber: Penulis, 2021 


\section{KESIMPULAN DAN SARAN}

\section{Kesimpulan}

Terwujudlah sebuah ruang rekreasi dengan program Healthy Market, Fitness facility, Food Hub, dan Fruit Garden yang mampu meningkatkan tingkat gizi dan pola hidup sehat di lingkungan ekologi perkotaan dalam hal ini berlokasi di Sawangan, Depok yang sedang berkembang menjadi kota metropolitan. Hasil akhir rancangan ini mampu memenuhi tujuannya yakni menyediakan kebutuhan konsumsi gizi yang sehat, mendistribusikan produk seputar healthy lifestyle, meningkatkan kesadaran pentingnya hidup sehat, serta mewadahi aktivitas olahraga dan rekreasi masyarakat.

\section{Saran}

Proyek semacam ini dapat dibangun di lokasi lain dengan kriteria yang serupa mengingat pentingnya kesehatan fisik dan mental masyarakat dalam konteks perkotaan. Perlunya penyesuaian kebutuhan ruang sesuai lingkungannya untuk menghasilkan ruang yang sesuai kebutuhan masyarakat sekitar.

\section{REFERENSI}

Belshaw, C. (1981). Tukar-Menukar Tradisional dan Pasar Modern. Jakarta: Gramedia.

Dinas Kesehatan Kota Depok. (2019). Profil Kesehatan Kota Depok 2019. Depok: Dinas Kesehatan Kota Depok

Kementrian PPN/Bappenas. (2019). Kajian Sektor Kesehatan Pembangunan Gizi di Indonesia. Jakarta: Kementrian PPN/Bappenas

Lynch, K. (1960). The Image Of The City. Massachusetts: M.I.T.

Sutanto, A. (2020). Peta Metode Desain. Jakarta: Untar 
